\title{
Novel HEXOL-type cyclometallated iridium(III) complexes: stereoselective synthesis and structure elucidation $\dagger$
}

\author{
Liangru Yang, ${ }^{a}$ Alex von Zelewsky ${ }^{* a}$ and Helen Stoeckli-Evans ${ }^{b}$ \\ Received (in Cambridge, UK) 3rd June 2005, Accepted 30th June 2005 \\ First published as an Advance Article on the web 28th July 2005 \\ DOI: $10.1039 / b 507769 a$
}

Two diastereoisomers of tetranuclear cyclometallated iridium complexes, either having an inner core of HEXOL-type $\left[\operatorname{Ir}\left(\operatorname{IrCl}_{2}\right)_{3}\right]^{6+}$ unit and a surface of six chiral, didentate, cyclometallated ligands, are stereoselectively synthesized from an enantiopure pinenopyridine derivative.

The motif of an octahedral coordination center surrounded by three didentate "ligands", which constitute themselves octahedral coordination entities (HEXOL-type), has been of interest since the classical work of Alfred Werner, ${ }^{1}$ mainly due to the inherently chiral nature of such structures. ${ }^{2}$ In the present communication we describe tetranuclear iridium(III) complexes of the HEXOL-type, which have some remarkable structural features.

The reaction of iridium trichloride hydrate with enantiopure 2-phenyl-4,5-pinenopyridine derivative (-)- $\mathrm{HL}^{\mathrm{I}}{ }^{3}$, in a refluxing mixture of 2-ethoxyethanol and water, leads to the formation of a yellow precipitate (Scheme 1). Flash chromatography on silica column gives two diastereoisomers $\mathbf{1}$ and $\mathbf{2}+$ Crystals of $\mathbf{1}$ and $\mathbf{2}$ were obtained from $\mathrm{CH}_{2} \mathrm{Cl}_{2} / n$-hexane and $\mathrm{CH}_{3} \mathrm{COOC}_{2} \mathrm{H}_{5} /$ diethyl ether, respectively. X-Ray crystallography ${ }^{4,5}$ revealed the formation of the HEXOL-type tetranuclear iridium complexes, as shown in Fig. 2.

The inner core of either molecule is a HEXOL-type $\left[\operatorname{Ir}\left(\operatorname{IrCl}_{2}\right)_{3}\right]^{6+}$ tetranuclear unit, which by itself has $D_{3}$-symmetry. The "surface" of these coordination species is formed by six chiral, didentate, cyclometallated ligands, which results in uncharged molecular complexes. These complexes are highly soluble in $\mathrm{CH}_{2} \mathrm{Cl}_{2}$,

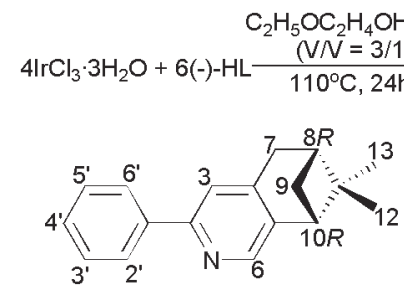

$(-)-\mathrm{HL}^{\prime}$

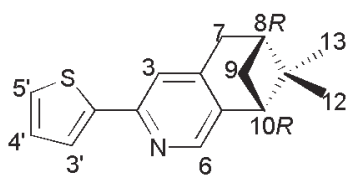

$(-)-H L^{\prime \prime}$
Scheme 1 Synthesis of the complexes and their numbering scheme for NMR.

${ }^{a}$ Department of Chemistry, University of Fribourg, Pérolles, 1700 Fribourg, Switzerland.E-mail: Alexander.vonzelewsky@unifr.ch; Fax: +41 26 3009738; Tel: +41263008732

${ }^{b}$ Institute of Chemistry, University of Neuchâtel, Avenue de Bellevaux 51, 2007 Neuchâtel, Switzerland. E-mail: Helen.Stoeckli-

Evans@unine.ch; Fax: + 4132 7182511; Tel: + 41327182426

$\uparrow$ Electronic supplementary information (ESI) available: X-Ray crystal structure of complex 3 and spectral properties of complexes 1-4. See http:// dx.doi.org/10.1039/b507769a
$\mathrm{CH}_{3} \mathrm{COOC}_{2} \mathrm{H}_{5}$ and many other low polar organic solvents due to the nearly complete coverage of the molecular surface by the phenyl-pinenopyridine groups.

Of particular interest is the stereochemistry of these tetranuclear species. Each of the three peripheral iridium atoms, are bound to two $\mathrm{C}, \mathrm{N}$-coordinating phenyl-pinenopyridine ligands, adopting a $\mathrm{N}, \mathrm{N}$-trans, C,C-cis arrangement. Thus, all the four iridium atoms can have either $\Delta$-, or $\Lambda$-configuration and there are eight possible stereoisomers of the tetranuclear HEXOL-type complex $\left[\operatorname{Ir}\left(\operatorname{IrCl}_{2}(-)-\mathrm{L}_{2}\right)_{3}\right]$. Four kinds of $D_{3}$-symmetric species will occur when all the three peripheral iridium atoms have the same configuration (Scheme 2, I), while another four kinds of $C_{2}$-symmetric species can be formed when one of the three peripheral iridium atoms has an opposite configuration and breaks the $D_{3}$-symmetry (Scheme 2, II). Using enantiopure organic ligands, the stereoselectivity of the formation of such complexes can be investigated.

An NMR investigation of all products formed in Scheme 1 revealed that only two diastereoisomers, were formed and the ratio of 1 to 2 was determined to be $5: 3$. Fig. 3 illustrates the aromatic region of the ${ }^{1} \mathrm{H}$ NMR spectra of complexes $\mathbf{1}$ and 2 . These spectra, as well as the ${ }^{13} \mathrm{C}$ NMR spectra, show, in each case, the presence of three sets of ligands. Therefore, both complexes are $C_{2^{-}}$ symmetric species, according to the occurrence of three types of magnetically non-equivalent ligands $\mathrm{L}^{\mathrm{I}}, \mathrm{L}^{\mathrm{I}}$ and $\mathrm{L}^{\mathrm{I} \prime}$ in $C_{2^{-}}$ symmetric configuration (scheme 2, II). None of the highest possible $D_{3}$-symmetric molecules is formed, since in this case, all six ligands would be magnetically equivalent.

Indeed, a close inspection of the X-ray structures in Fig. 2 shows that $C_{2}$-symmetry is present and in both cases, the central iridium atoms show $\Delta$-configuration. In complexes $\mathbf{1}$ and $\mathbf{2}$, the three

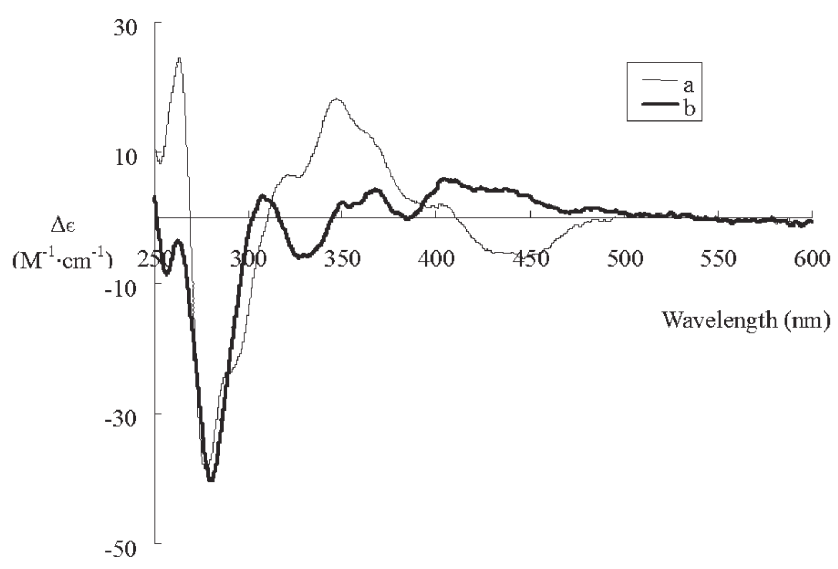

Fig. $1 \mathrm{CD}$ spectra of complexes 1 (a) and 2 (b) $\left(\mathrm{RT}\right.$, in $\left.\mathrm{CH}_{2} \mathrm{Cl}_{2}\right)$. 


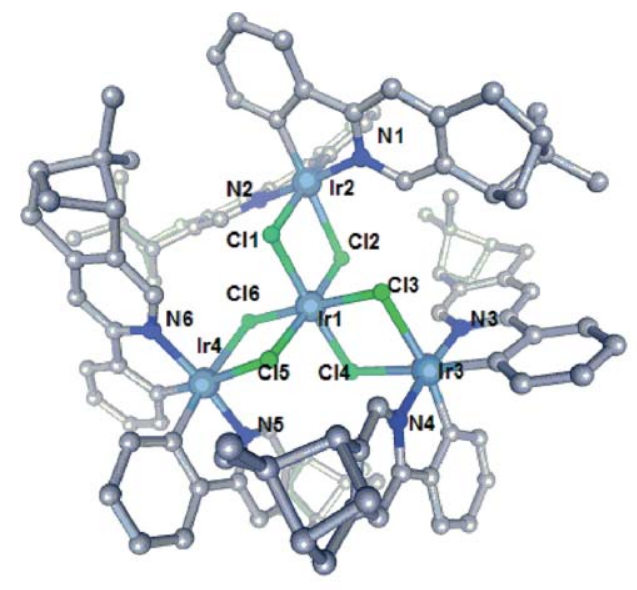

(a)

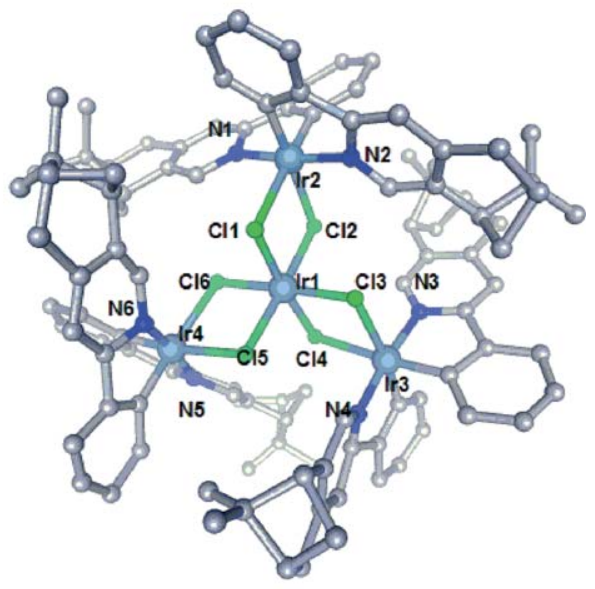

(b)

Fig. 2 X-Ray crystal structures of complexes 1 (a) and 2 (b).
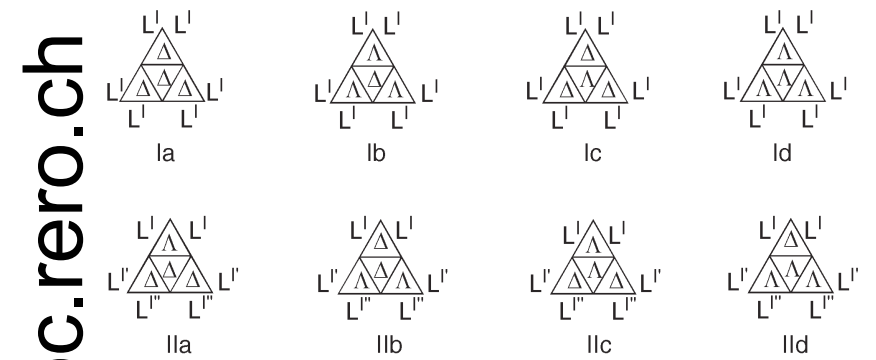

을

Scheme 2 Eight possible stereoisomers of the tetranuclear HEXOL-type complex $\left[\operatorname{Ir}\left(\operatorname{IrCl}_{2}(-)-\mathrm{L}_{2}\right)_{3}\right]$.
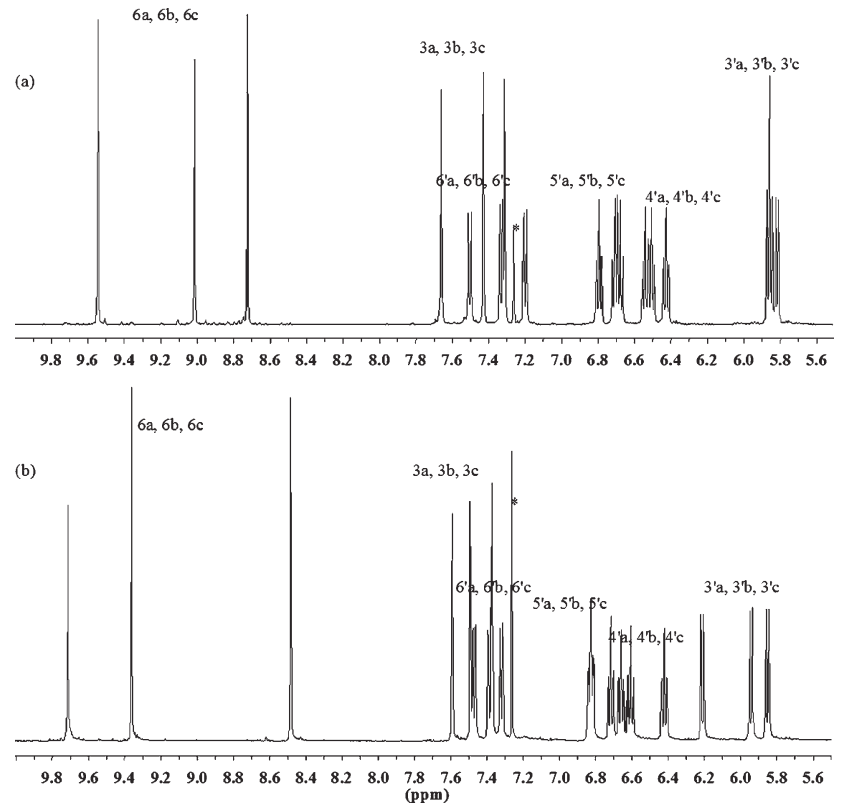

Fig. 3 Aromatic region of the ${ }^{1} \mathrm{H}$ NMR spectra of complexes $\mathbf{1}$ (a) and $\mathbf{2}$ (b) $\left(500 \mathrm{MHz}, \mathrm{CDCl}_{3}(*), \mathrm{RT}\right)$. peripheral iridium atoms, Ir2, Ir3 and $\operatorname{Ir} 4$, have $\Delta^{-}, \Lambda$-, $\Lambda$ - and $\Delta^{-}$, $\Lambda$-, $\Delta$-configurations, respectively. Thus, the products obtained from the reaction of ligand $(-)-\mathrm{HL}^{\mathrm{I}}$ are stereoisomers $\Delta-\operatorname{Ir}\left(\Delta-\operatorname{IrCl}_{2}\left(\{\mathrm{C}, \mathrm{C}-\text { cis-N,N-trans }\}(-)-\mathrm{L}^{\mathrm{I}}\right)_{2}\right)\left(\Lambda-\mathrm{IrCl}_{2}(\{\mathrm{C}, \mathrm{C}-\right.$ cis-N,Ntrans $\left.\left.\}(-)-\mathrm{L}^{\mathrm{I}}\right)_{2}\right)_{2}, 1$ (Scheme 2, IIb), and $\Delta-\operatorname{Ir}\left(\Delta-\operatorname{IrCl}_{2}(\{\mathrm{C}, \mathrm{C}-\right.$ cis$\left.\left.\mathrm{N}, \mathrm{N}-\operatorname{trans}\}(-)-\mathrm{L}^{\mathrm{I}}\right)_{2}\right)_{2}\left(\Lambda-\mathrm{IrCl}_{2}\left(\{\mathrm{C}, \mathrm{C}-\text { cis-N,N-trans }\}(-)-\mathrm{L}^{\mathrm{I}}\right)_{2}\right), \quad \mathbf{2}$ (Scheme 2, IIa), respectively.

A related ligand, (-)-HL ${ }^{\text {II }}, 6$ (Scheme 1) yielded analogous complexes $\mathbf{3}$ and $\mathbf{4}$. The ratio of the two isomers is somewhat different in this case $(1: 5)$.

Thus, stereoselectivity is complete as far as the configuration of the central iridium is concerned. It appears only in the $\Delta$-configuration, using the (-)-HL $\mathrm{HL}^{\mathrm{I}}$ II ligands. The occurrence of mixed configurations, $\Delta-, \Lambda_{-}, \Lambda$-, and $\Delta-, \Lambda-, \Delta-$, respectively, of the peripheral iridium atoms is rather surprising. Under the same conditions, the reaction of iridium trichloride hydrate with unsubstituted phenylpyridine ( $\mathrm{HPhPy}$ ) yields a Cl-bridged dinuclear cyclometallated compound $\left[\mathrm{Ir}(\mathrm{PhPy})_{2} \mathrm{Cl}_{2}\right]_{2}{ }^{7}$ Thus, the formation of the tetranuclear species with phenyl pinenopyridine derivatives is caused by the pinene group annellated to the pyridine ring.

\section{Notes and references}

\$ Iridium trichloride hydrate $(0.3 \mathrm{mmol})$ was combined with $\mathrm{HL}^{\mathrm{I}}$, dissolved in a mixture of 2-ethoxyethanol $(15 \mathrm{~mL})$ and water $(5 \mathrm{~mL})$, and heated at $110{ }^{\circ} \mathrm{C}$ for $24 \mathrm{~h}$. The solution was cooled to RT. The yellow precipitate formed was collected and washed with ethanol to give a mixture of $\mathbf{1}$ and $\mathbf{2}$ in the ratio of $5: 3$. The mixture was then separated by flash chromatography on silica column using $\mathrm{CH}_{2} \mathrm{Cl}_{2} / n$-hexane $1: 1$ as eluent to yield two diastereoisomers $\mathbf{1}(70 \mathrm{mg}, 38 \%)$ and $\mathbf{2}(42 \mathrm{mg}, 23 \%)$. The relative $R_{\mathrm{f}}$ value of complexes $\mathbf{1}$ and $\mathbf{2}$ are 0.52 and 0.40 , respectively. Fig. 1 displays the CD spectra of complexes $\mathbf{1}$ and $\mathbf{2}$.

$\S$ CCDC 269178. See http://dx.doi.org/10.1039/b507769a for crystallographic data in CIF or other electronic format.

- CCDC 269179. See http://dx.doi.org/10.1039/b507769a for crystallographic data in CIF or other electronic format.

1 A. Werner, E. Berl, E. Zinggeler and G. Jantsch, Ber. Dtsch. Chem. Ges., 1907, 40, 2103-2125; A. Werner, Ber. Dtsch. Chem. Ges., 1914, 47, 3087-3094.

2 W. G. Jackson, J. A. McKeon, M. Zehnder, M. Neuberger and S. Fallab, Chem. Commun., 2004, 20, 2322-2323; I. Bernal, M. T. Gonzalez, 
J. Cetrullo and J. Cai, Struct. Chem., 2001, 12, 73-79; I. Bernal, J. Cetrullo and S. Berhane, J. Coord. Chem., 2000, 52, 185-205; Y. Shimura, Rev. Inorg. Chem., 1984, 6, 149-193; D. J. Hodgson, K. Michelsen, E. Pedersen and D. K. Towle, J. Chem. Soc., Chem. Commun., 1988, 6, 426-428; D. J. Hodgson, K. Michelsen, E. Pedersen and D. K. Towle, Inorg. Chem., 1991, 30, 815-822.

3 L. Ghizdavu, O. Lentzen, S. Schumm, A. Brodkorb, C. Moucheron and A. Kirsch-De Mesmaeker, Inorg. Chem., 2003, 42, 1935-1944.

4 X-Ray data for $\mathbf{1 . 2}\left(\mathbf{C H}_{2} \mathbf{C l}_{2}\right): \mathrm{C}_{110} \mathrm{H}_{112} \mathrm{Cl}_{10} \mathrm{Ir}_{4} \mathrm{~N}_{6}, M_{\mathrm{r}}=2641.36$, yellow rod, $0.34 \times 0.11 \times 0.09 \mathrm{~mm}^{3}, F(000)=5168$. Orthorhombic, space group $P 22_{1} 2_{1} 2_{1}, a=18.7702(8), b=21.6033(11), c=28.1507(12) \AA$, $\alpha=\beta=\gamma=90^{\circ}, V=11415.1(9) \AA^{3}, Z=4, \rho_{\text {calcd }}=1.537 \mathrm{~g} \mathrm{~cm}^{-3}$. Data collection at $173 \mathrm{~K}$ on a Stoe Image Plate Diffraction System, by using graphite monochromated Mo-K $\alpha$ radiation $(\lambda=0.71073 \AA)$. Image plate distance: $70 \mathrm{~mm}, \phi$ oscillation scans $0-200^{\circ}$, step $\Delta \phi=0.8^{\circ}, 2 \theta=3.27$ $52.1^{\circ}, d_{\min } / d_{\max }=12.45 / 0.81 \AA$. A total of 38417 reflections collected of which 18654 reflections were independent and used to refine 1129 parameters. 13655 observed reflections with $I>2 \sigma(I)$. $R_{1}=0.0314$, $w R_{2}=0.0544$ (observed); $R_{1}=0.0490, w R_{2}=0.0574$ (all data). The structure was solved by direct methods (SHELXS-97) and refined anisotropically, using weighted full-matrix least-squares on $F^{2}$ (SHELXL-97). The H-atoms were included in calculated positions and treated as riding atoms. Max./min. residue electron density

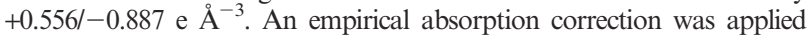
using the DELrefABS routine in PLATON (A. L. Spek, J. Appl. Cryst., 2003, 36, 7-13); transmission factors: $T_{\min } / T_{\max }=0.507 / 0.844$. A region of disordered electron density was removed using the SQUEEZE routine in PLATON; 290 electrons for a volume of $3009 \AA^{3}$. This was assumed to be equivalent to 2 molecules of dichloromethane per molecule of complex. Certain C-atoms on the exterior of the molecule undergo higher thermal motion than those at the interior of the molecule. The atomic coordinates correspond to the absolute structure of the molecule in the crystal. § Flack parameter $x=-0.018(5)$.
5 X-Ray data for $\mathbf{2} \cdot \mathbf{3}\left(\mathbf{C H}_{3} \mathbf{C O O C}_{2} \mathbf{H}_{5}\right): \mathrm{C}_{120} \mathrm{H}_{132} \mathrm{Cl}_{6} \mathrm{Ir}_{4} \mathrm{~N}_{6} \mathrm{O}_{6}, M_{\mathrm{r}}=2735.82$, yellow block, $0.30 \times 0.15 \times 0.10 \mathrm{~mm}^{3}, F(000)=5408$. Orthorhombic, space group $P 2_{1} 2_{1} 2_{1}, a=18.5074(13), b=21.1473(16), c=28.8458(17) \AA$, $\alpha=\beta=\gamma=90^{\circ}, V=11289.7(13) \AA^{3}, Z=4, \rho_{\text {calcd }}=1.610 \mathrm{~g} \mathrm{~cm}^{-3}$. Data collection at $173 \mathrm{~K}$ on a Stoe Mark II-Image Plate Diffraction System equipped with a two-circle goniometer, by using $\mathrm{Mo}-\mathrm{K} \alpha$ graphite monochromated radiation $(\lambda=0.71073 \AA)$. Image plate distance: $135 \mathrm{~mm}, \omega$ rotation scans $0-180^{\circ}$ at $\phi 0^{\circ}$, step $\Delta \phi=1.0^{\circ}$, with an exposure time of $8 \mathrm{~min}$ per image, $2 \theta$ range $1.70-51.55^{\circ}$, $d_{\min } / d_{\max }=23.995 / 0.817 \AA$. A total of 54825 reflections of which 20065 reflections were independent and used to refine 577 parameters. 8345 observed reflections with $I>2 \sigma(I) . R_{1}=0.0710, w R_{2}=$ 0.1457 (observed); $R_{1}=0.1353, w R_{2}=0.1738$ (all data). The structure was solved by direct methods (SHELXS-97) and only the $\mathrm{Ir}, \mathrm{Cl}$ and $\mathrm{N}$ atoms were refined anisotropically, while the $\mathrm{C}$ atoms were refined isotropically, using weighted full-matrix least-squares on $F^{2}$ (SHELXL97). The H-atoms were included in calculated positions and treated as riding atoms. Max./min. residue electron density $+0.843 /-1.443$ e $\AA^{-3}$. An empirical absorption correction was applied using the DELrefABS routine in PLATON (A. L. Spek, J. Appl. Cryst., 2003, 36, 7-13); transmission factors: $T_{\min } / T_{\max }=0.033 / 0.426$. A region of disordered electron density was removed using the SQUEEZE routine in PLATON; 658 electrons for a volume of $2819 \AA^{3}$. This was assumed to be equivalent to 3 molecules of $\mathrm{CH}_{3} \mathrm{COOCH}_{2} \mathrm{CH}_{3}$ per molecule of complex. Attempts to refine the $\mathrm{C}$ atoms anisotropically were unsuccessful. The crystal diffracted weakly beyond $40^{\circ}$ in $2 \theta$ and only $42 \%$ of the data can be considered to be observed $I>2 \sigma(I)$. The atomic coordinates correspond to the absolute structure of the molecule in the crystal. $\uparrow$ Flack parameter $x=0.013(15)$.

6 M. Gianini, A. Forster, P. Haag, A. von Zelewsky and H. StoeckliEvans, Inorg. Chem., 1996, 35, 4889-4895.

7 S. Sprouse, K. A. King, P. J. Spellane and R. J. Watts, J. Am. Chem. Soc., 1984, 106, 6647-6653. 